\title{
Impact of surgical margin status on the outcome of bladder cancer treated by radical cystectomy: a meta-analysis
}

\author{
Xuwei Hong ${ }^{1, *}$, Tieqiu Li ${ }^{2, *}$, Fengsheng Ling ${ }^{1, *}$, Dashan Yang ${ }^{1}$, Lina Hou ${ }^{3, *}$, Fei $\mathrm{Li}^{1, *}$ \\ and Wanlong Tan ${ }^{1, *}$ \\ ${ }^{1}$ Department of Urology, Nanfang Hospital, Southern Medical University, Guangzhou, Guangdong, P. R. China \\ 2 Department of Urology, The People's Hospital of Hunan Province, First Affiliated Hospital of Hunan Normal University, \\ Changsha, P. R. China \\ ${ }^{3}$ Department of Healthy Management, Nanfang Hospital, Southern Medical University, Guangzhou, Guangdong, P. R. China. \\ * These authors have contributed equally to this work \\ Correspondence to: Wanlong Tan, email: twl@smu.edu.cn
}

Fei Li, email: feili20700338@126.com

Lina Hou, email: Ihhou2010@126.com

Keywords: bladder cancer, surgical margin status, radical cystectomy, outcome, meta-analysis

Received: April 29, $2016 \quad$ Accepted: October 14, $2016 \quad$ Published: October 25, 2016

\section{ABSTRACT}

Data regarding the association between surgical margin status and the outcome of bladder cancer treated by radical cystectomy (RC) are conflicting. Therefore, the present meta-analysis was performed to assess the associations between the outcomes of bladder cancer, in terms of recurrence-free survival (RFS), cancerspecific survival (CSS) and overall survival (OS), and the presence of positive surgical margins versus negative surgical margins following treatment with RC. Research articles published prior to April 2016 were identified from Pubmed, Embase and the Cochrane Library databases. A total of $\mathbf{3 6}$ articles were included, with a sample size of 38,384 bladder cancer patients. Of these, 4,354 patients were reported to have positive surgical margins. Significant associations were detected between positive surgical margins following RC and unfavorable RFS [summary relative risk estimate (SRRE), 1.63; 95\% confidence interval (CI), 1.46-1.83; $P=0.105]$, CSS (SRRE, 1.82; 95\% CI, 1.63-2.04; $P=0.001$ ) and OS (SRRE, 1.68; 95\% CI, 1.58-1.80; $P=0.805$ ), by fixed or random effects models. The findings were consistent independently of age, sample size, publication year, follow-up duration, study type and geographical region. In summary, the present findings demonstrate that the presence of positive surgical margins is associated with poor survival outcomes in bladder cancer following RC, indicating that avoidance of positive surgical margins during surgery is helpful to improve the prognosis of patients with bladder cancer.

\section{INTRODUCTION}

Bladder cancer is the ninth most commonly diagnosed cancer worldwide and ranks second in terms of incidence among genitourinary malignancies. The American Cancer Society estimated that in the United States there were 76,960 new cases and 16,390 mortalities from bladder cancer in 2016 [1]. A trend of increasing incidence and mortality rates has been observed in the past three decades. Radical cystectomy (RC) is the standard treatment for muscle-invasive bladder cancer and non-muscle-invasive bladder cancers with high-risk features [2]. Although minimally invasive techniques have increased in application, with the goal of minimizing patient mortality, the mortality associated with bladder cancer following $\mathrm{RC}$ has not changed substantially in the last 30 years [3]. Research regarding the effects of risk factors on the survival outcomes of bladder cancer following treatment with RC remains important. Currently, the stage and grade of tumors are used as the major prognostic factors for these patients [3]. However, there is growing interest in identifying additional prognostic indicators to aid medical professionals in improving prognostic evaluation. 
Surgical margin status is determined by the presence or absence of tumor tissue in the areas of soft tissue around the surgical specimen. Although the potential associations between surgical margin status and survival outcome have received much attention in the past few years, studies have yielded inconsistent results. Several large retrospective studies have demonstrated that positive surgical margins are an independent predictor of recurrence and eventual mortality from bladder cancer [4-6]. On the contrary, other studies demonstrated that positive surgical margins were not independently associated with the risk of local recurrence or the disease-free survival of bladder cancer patients after $\mathrm{RC}$, indicating that surgical margin status may not be a significant factor in determining the eventual prognosis compared with other widely accepted prognostic indicators [7-9]. To date, no quantitative assessment concerning the association of surgical margin status with outcomes in bladder cancer following treatment with RC has been conducted.

In the present study, a meta-analysis was conducted to summarize the relationship between surgical margin status and bladder cancer outcome after RC based on all published epidemiological studies. The purpose of this meta-analysis was to clarify the association between surgical margin status and survival outcomes of RC, and explore potential sources of heterogeneity across different studies.

\section{RESULTS}

\section{Search results}

Figure 1 illustrates the process of the literature search. Briefly, a total of 2,761 articles were identified

2761 articles identified through literature search

Pubmed:1202; Embase:1445; Cochrance:114

1041 duplicate articles

1720 articles after duplicates removed

1470 excluded:

not relevant studies, mechanism studies, case reports, reviews, meta-analyses, comments, etc

250 potentially relevant articles reviewed

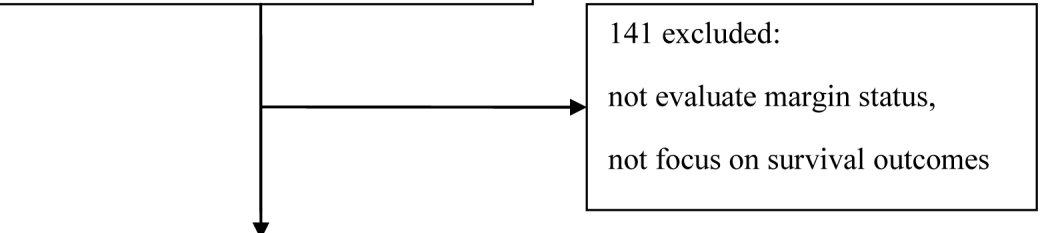

109 full-text articles reviewed

73 excluded:

Not evaluate the associations between margin status and outcomes of RC $(n=24)$

Without extractable data $(n=32)$

Duplicate patient population $(n=17)$

36 articles included

Articles reported RFS ( $\mathrm{n}=16)$

Articles reported CSS $(\mathrm{n}=26)$

Articles reported OS $(n=18)$

Figure 1: Flow chart illustrating the study selection. 
Table 1: Characteristics of studies included in meta-analysis of surgical margin status and bladder cancer outcomes.

\begin{tabular}{|c|c|c|c|c|c|c|c|c|}
\hline Study & Country/Type & Period & $\begin{array}{l}\text { Mean } \\
\text { follow } \\
\text {-up(months) }\end{array}$ & $\begin{array}{l}\text { Mean } \\
\text { age }\end{array}$ & $\begin{array}{l}\text { Sample- } \\
\text { size }\end{array}$ & \begin{tabular}{|l} 
Positive \\
SM(\%)
\end{tabular} & $\begin{array}{l}\text { Positive } \\
\text { LN(\%) }\end{array}$ & T stage $(\%)$ \\
\hline Soave 2015 [21] & Germany; single-center study & 1996-2011 & 45.0 & 67.0 & 517 & 12.0 & 26.7 & $\leq \mathrm{T} 2: 55.5 ; \geq \mathrm{T} 3: 44.5$ \\
\hline $\begin{array}{l}\text { Satkunasivam } 2015 \\
{[10]}\end{array}$ & USA; single-center study & 1971-2009 & 148.8 & 66.2 & 2047 & 0.0 & NA & $\leq \mathrm{T} 2: 63.3 ; \geq \mathrm{T} 3: 36.7$ \\
\hline Reder 2015 [8] & USA; single-center study & 2000-2012 & 20.0 & 67.9 & 364 & 10.7 & 20.0 & $\leq \mathrm{T} 2: 54.1 ; \geq \mathrm{T} 3: 44.5$ \\
\hline Raza 2015 [34] & International multicenter study & 2003-2015 & 67.0 & 69.0 & 702 & 8.0 & 21.0 & $\leq \mathrm{T} 2: 62.0 ; \geq \mathrm{T} 3: 38.0$ \\
\hline Kanatani 2015 [29] & Japan; single-center study & 1990-2012 & 29.0 & 64.0 & 61 & 11.5 & 50.8 & $\leq \mathrm{T} 2: 13.1 ; \geq \mathrm{T} 3: 86.9$ \\
\hline Gakis 2015 [35] & International multicenter study & 1994-2011 & 64.0 & 54.0 & 297 & 2.4 & 20.2 & $\leq \mathrm{T} 2: 40.4 ; \geq \mathrm{T} 3: 59.6$ \\
\hline Booth 2015 [11] & Canada; single-center study & 1994-2008 & NA & 72.0 & 2802 & 13.0 & 29.0 & $\leq \mathrm{T} 2: 29.0 ; \geq \mathrm{T} 3: 71.0$ \\
\hline Aziz 2015 [36] & International multicenter study & 1989-2011 & 40.0 & 68.0 & 856 & 24.8 & 53.6 & $\leq \mathrm{T} 2: 0.0 ; \geq \mathrm{T} 3: 100.0$ \\
\hline Albisinni 2015 [22] & International multicenter study & $2000-2013$ & 50.0 & 68.0 & 503 & 5.8 & 23.1 & $\leq \mathrm{T} 2: 57.9 ; \geq \mathrm{T} 3: 42.1$ \\
\hline Yuh 2014 [12] & USA; single-center study & 2004-2012 & 52.0 & 70.0 & 162 & 4.3 & 21.6 & $\leq \mathrm{T} 2: 66.7 ; \geq \mathrm{T} 3: 33.3$ \\
\hline Suer 2014 [30] & Turkey; single-center study & 1990-2012 & 37.7 & 66.5 & 290 & 7.6 & 14.5 & $\leq \mathrm{T} 2: 54.8 ; \geq \mathrm{T} 3: 45.2$ \\
\hline Sejima 2014 [31] & Japan; single-center study & 2003-2011 & 24.8 & 71.1 & 249 & 4.4 & 15.7 & $\leq \mathrm{T} 2: 56.6 ; \geq \mathrm{T} 3: 43.4$ \\
\hline Ploussard 2014 [37] & International multicenter study & 1979-2012 & 32.2 & 68.0 & 8141 & 23.7 & 23.7 & $\leq \mathrm{T} 2: 56.8 ; \geq \mathrm{T} 3: 43.2$ \\
\hline $\begin{array}{l}\text { Nieuwenhuijzen } 2014 \\
\text { [23] }\end{array}$ & Netherlands; single-center study & 1990-2006 & 64.0 & 62.3 & 343 & 10.0 & 34.0 & $\leq \mathrm{T} 2: 52.0 ; \geq \mathrm{T} 3: 48.0$ \\
\hline May 2014 [24] & International multicenter study & 1989-2008 & 36.0 & 67.0 & 385 & 22.3 & 51.4 & $\leq \mathrm{T} 2: 0.0 ; \geq \mathrm{T} 3: 100.0$ \\
\hline Lin 2014 [12] & USA; single-center study & 1990-2010 & 66.0 & 68.0 & 196 & 0.0 & NA & $\leq \mathrm{T} 2: 100.0 ; \geq \mathrm{T} 3: 0.0$ \\
\hline Kluth 2014 [38] & International multicenter study & 1998-2010 & 36.1 & 67.0 & 2895 & 5.5 & 26.9 & $\leq \mathrm{T} 2: 53.9 ; \geq \mathrm{T} 3: 46.1$ \\
\hline Klatte 2014 [39] & International multicenter study & 1979-2012 & 41.0 & 67.5 & 7906 & 5.3 & 23.8 & $\leq \mathrm{T} 2: 58.1 ; \geq \mathrm{T} 3: 41.9$ \\
\hline Bruins 2014 [25] & Netherlands; single-center study & 1998-2011 & 75.6 & 65.0 & 245 & 2.9 & NA & $\leq \mathrm{T} 2: 64.9 ; \geq \mathrm{T} 3: 35.1$ \\
\hline Bachir 2014 [14] & Canada; multicenter study & 1998-2008 & 39.0 & 65.6 & 847 & 10.6 & 22.4 & $\leq \mathrm{T} 2: 49.8 ; \geq \mathrm{T} 3: 50.2$ \\
\hline Lotan 2013 [9] & USA; single-center study & 2007-2012 & 20.0 & 70.0 & 216 & 7.0 & 25.0 & $\leq \mathrm{T} 2: 60.0 ; \geq \mathrm{T} 3: 40.0$ \\
\hline Fritsche 2013 [26] & Germany; multicenter study & 2006-2010 & 20.0 & 69.0 & 158 & 26.6 & 100.0 & $\leq \mathrm{T} 2: 19.6 ; \geq \mathrm{T} 3: 80.4$ \\
\hline Todenhofer 2012 [27] & Germany; single-center study & 1999-2010 & 30.0 & 67.8 & 258 & 10.1 & 27.1 & $\leq \mathrm{T} 2: 50.4 ; \geq \mathrm{T} 3: 49.6$ \\
\hline Mitra 2012 [15] & USA; single-center study & 1971-2005 & 31.2 & 62.3 & 447 & 7.8 & 48.8 & $\leq \mathrm{T} 2: 26.6 ; \geq \mathrm{T} 3: 24.6$ \\
\hline Gondo 2012 [32] & Japan; single-center study & 2000-2009 & 26.8 & 68.0 & 194 & 10.3 & 10.8 & $\leq \mathrm{T} 2: 55.7 ; \geq \mathrm{T} 3: 44.3$ \\
\hline Yafi 2011 [16] & Canada; multicenter study & 1998-2008 & 35.0 & 68.0 & 2287 & 8.6 & 25.9 & $\leq \mathrm{T} 2: 48.1 ; \geq \mathrm{T} 3: 51.9$ \\
\hline Sonpavde $2011[40]$ & International multicenter study & 1971-2008 & 39.4 & 68.5 & 578 & 4.0 & 0.0 & $\leq \mathrm{T} 2: 0.0 ; \geq \mathrm{T} 3: 100.0$ \\
\hline Hofner 2011 [28] & Germany; single-center study & 1990-2009 & 104.4 & 64.0 & 328 & 17.0 & 36.0 & $\leq \mathrm{T} 2: 49.0 ; \geq \mathrm{T} 3: 51.0$ \\
\hline Tilki 2010 [41] & International multicenter study & 1979-2008 & 55.0 & 68.9 & 583 & 24.9 & 53.5 & $\leq \mathrm{T} 2: 0.0 ; \geq \mathrm{T} 3: 100.0$ \\
\hline Kim 2010 [33] & Korea; single-center study & 1986-2005 & 66.3 & 60.8 & 406 & 3.9 & 12.1 & $\leq \mathrm{T} 2: 67.2 ; \geq \mathrm{T} 3: 32.8$ \\
\hline Fairey 2009 [17] & Canada; single-center study & 1994-2007 & 31.0 & 66.0 & 523 & 12.0 & 23.0 & $\leq \mathrm{T} 2: 49.0 ; \geq \mathrm{T} 3: 51.0$ \\
\hline Chapman 2009 [18] & USA; single-center study & 1996-2006 & 34.3 & 66.4 & 308 & 12.7 & 27.3 & $\leq \mathrm{T} 2: 49.0 ; \geq \mathrm{T} 3: 51.0$ \\
\hline Canter 2009 [19] & USA; single-center study & 1988-2006 & 46.4 & 65.5 & 344 & 11.6 & NA & $\leq \mathrm{T} 2: 89.0 ; \geq \mathrm{T} 3: 11.0$ \\
\hline Dotan 2007 [4] & USA; single-center study & $1985-2005$ & NA & 65.9 & 1589 & 4.2 & 24.0 & $\leq \mathrm{T} 2: 54.0 ; \geq \mathrm{T} 3: 46.0$ \\
\hline Lee 2006 [7] & Korea; single-center study & 1995-2002 & 37.1 & 61.0 & 115 & 4.3 & 0.0 & NA \\
\hline Herr 2004 [20] & USA; multicenter study & 1987-1998 & 106.8 & 64.6 & 242 & 10.0 & 20.5 & $\leq \mathrm{T} 2: 69.0 ; \geq \mathrm{T} 3: 31.0$ \\
\hline
\end{tabular}

Abbreviations: SM, surgical margin; LN, lymph node; NA, data not applicable

using our search strategy, of which 250 were considered potentially relevant articles after excluding duplicate articles and screening the titles and abstracts. A further 141 articles were excluded because that they did not evaluate margin status, or did not focus on survival outcomes. After assessing the remaining 109 articles by full-text review, 73 articles were excluded; of these, 24 articles did not investigate the associations between surgical margin status and survival outcomes of bladder cancer in patients who had undergone RC, 32 were excluded because they did not report relative risk estimates and the corresponding 95\% CI or did not provide the sufficient data to calculate them, and 17 articles were excluded as the participants overlapped with other studies. Finally, a total of 36 articles were included in the meta-analysis. The outcomes used were recurrence-free survival (RFS) in 16 studies, cancerspecific survival (CSS) in 26 studies and overall survival (OS) in 18 studies.

\section{Characteristics of the included studies}

The main characteristics of the included studies are shown in Table 1. All studies were published between 2004 and 2015, with the mean duration of follow-up varying from 20 to 148 months. Of the 36 studies, 14 were conducted in North America [4, 8-20], 8 in Europe [21-28], 6 in Asia [7, 29-33] and 8 at international multicenters [34- 
Table 2: Summary of meta-analysis results for surgical margin status and outcomes of RC.

\begin{tabular}{|c|c|c|c|c|c|}
\hline Analysis specification & Studies & SRRE $(95 \%$ CI $)$ & $\begin{array}{l}\text { Meta regression } \\
P \text {-value }\end{array}$ & $\begin{array}{l}\mathrm{H}^{2} \\
\text { Heterogeneity }\end{array}$ & $P$-value \\
\hline \multicolumn{6}{|l|}{ Recurrence-free survival } \\
\hline All & 16 & $1.63(1.46-1.83)$ & & 32.1 & 0.105 \\
\hline \multicolumn{6}{|l|}{ Mean age } \\
\hline$\geq 65$ & 13 & $1.61(1.43-1.81)$ & \multirow{2}{*}{0.259} & 34.8 & 0.104 \\
\hline$<65$ & 3 & $2.44(1.37-4.34)$ & & 0.0 & 0.419 \\
\hline \multicolumn{6}{|l|}{ Sample size } \\
\hline$\geq 500$ & 8 & $1.65(1.45-1.87)$ & \multirow{2}{*}{0.765} & 0.0 & 0.477 \\
\hline$<500$ & 8 & $1.56(1.16-2.10)$ & & 54.6 & 0.031 \\
\hline \multicolumn{6}{|l|}{ Published year } \\
\hline$\geq 2014$ & 12 & $1.73(1.50-1.99)$ & \multirow{2}{*}{0.257} & 3.4 & 0.411 \\
\hline$<2014$ & 4 & $1.45(1.18-1.78)$ & & 65.6 & 0.033 \\
\hline \multicolumn{6}{|l|}{ Mean follow-up } \\
\hline$\geq 60$ & 6 & $2.26(1.57-3.23)$ & \multirow{2}{*}{0.128} & 0.0 & 0.857 \\
\hline$<60$ & 10 & $1.57(1.39-1.78)$ & & 46.2 & 0.053 \\
\hline \multicolumn{6}{|l|}{ Study type } \\
\hline Single-center & 9 & $1.54(1.21-1.97)$ & \multirow{2}{*}{0.624} & 43.8 & 0.076 \\
\hline Multicenter & 7 & $1.66(1.46-1.83)$ & & 20.9 & 0.270 \\
\hline \multicolumn{6}{|l|}{ Region } \\
\hline America & 6 & $1.36(1.07-1.73)$ & \multirow{3}{*}{$\begin{array}{l}0.160 \\
0.306\end{array}$} & 51.0 & 0.070 \\
\hline Europe & 4 & $1.73(1.29-2.34)$ & & 0.0 & 0.861 \\
\hline Asia & 1 & $3.20(1.31-7.82)$ & & 1 & 1 \\
\hline \multicolumn{6}{|l|}{ Cancer-specific survival } \\
\hline All & 26 & $1.82(1.63-2.04)$ & & 54.5 & 0.001 \\
\hline \multicolumn{6}{|l|}{ Mean age } \\
\hline$\geq 65$ & 20 & $1.79(1.58-2.02)$ & \multirow{2}{*}{0.572} & 58.9 & 0.000 \\
\hline$<65$ & 6 & $2.00(1.49-2.68)$ & & 36.8 & 0.161 \\
\hline \multicolumn{6}{|l|}{ Sample size } \\
\hline$\geq 500$ & 12 & $1.74(1.59-1.91)$ & \multirow{2}{*}{0.662} & 24.8 & 0.200 \\
\hline$<500$ & 14 & $1.94(1.48-2.54)$ & & 67.1 & 0.000 \\
\hline \multicolumn{6}{|l|}{ Published year } \\
\hline$\geq 2014$ & 13 & $1.70(1.53-1.89)$ & \multirow{2}{*}{0.462} & 27.1 & 0.171 \\
\hline$<2014$ & 13 & $1.92(1.54-2.40)$ & & 66.2 & 0.000 \\
\hline Mean follow-up & & & & & \\
\hline$\geq 60$ & 4 & $2.30(1.72-3.09)$ & م 178 & 0.0 & 0.424 \\
\hline$<60$ & 20 & $1.77(1.54-2.04)$ & $0.4 / 2$ & 60.3 & 0.000 \\
\hline Study type & & & & & \\
\hline Single-center & 16 & $2.06(1.71-2.48)$ & & 58.4 & 0.002 \\
\hline Multicenter & 10 & $1.63(1.45-1.84)$ & 0.101 & 34.8 & 0.130 \\
\hline Region & & & & & \\
\hline America & 8 & $1.84(1.55-2.19)$ & 0.408 & 50.0 & 0.051 \\
\hline Europe & 7 & $1.97(1.40-2.75)$ & 0.618 & 68.8 & 0.004 \\
\hline Asia & 6 & $2.29(1.46-3.58)$ & & 57.1 & 0.040 \\
\hline Over survival & & & & & \\
\hline All & 18 & $1.68(1.58-1.80)$ & & 0.0 & 0.805 \\
\hline Mean age & & & & & \\
\hline$\geq 65$ & 16 & $1.68(1.58-1.80)$ & 0911 & 0.0 & 0.895 \\
\hline$<65$ & 2 & $1.72(1.23-2.39)$ & 0.911 & 69.3 & 0.071 \\
\hline Sample size & & & & & \\
\hline$\geq 500$ & 9 & $1.68(1.57-1.81)$ & 0905 & 0.0 & 0.610 \\
\hline$<500$ & 9 & 1.69 (1.44-1.97) & 0.995 & 0.0 & 0.693 \\
\hline Published year & & & & & \\
\hline
\end{tabular}




\begin{tabular}{|l|l|l|l|l|l|}
\hline$\geq 2014$ & 12 & $1.64(1.53-1.76)$ & \multirow{2}{*}{0.066} & 0.0 & 0.987 \\
\cline { 7 - 7 } & 6 & $1.95(1.66-2.28)$ & & 0.0 & 0.444 \\
\hline Mean follow-up & & & & & \\
\hline$\geq 60$ & 4 & $1.88(1.42-2.49)$ & \multirow{2}{*}{0.980} & 0.0 & 0.434 \\
\hline$<60$ & 13 & $1.65(1.53-1.79)$ & & 0.0 & 0.766 \\
\hline Study type & & & & & \\
\hline Single-center & 10 & $1.73(1.57-1.90)$ & \multirow{2}{*}{0.474} & 0.0 & 0.781 \\
\hline Multicenter & 8 & $1.65(1.51-1.80)$ & & 0.0 & 0.563 \\
\hline Region & & & & & \\
\hline America & 11 & $1.76(1.61-1.92)$ & \multirow{2}{*}{0.531} & 0.0 & 0.556 \\
\hline Europe & 3 & $1.68(1.31-2.17)$ & 0.698 & & 0.0 \\
\hline Asia & 1 & $1.52(1.01-2.42)$ & & $/$ & $/$ \\
\hline
\end{tabular}

41]. The meta-analysis was based on a total sample size of 38,384 patients, of which 4,354 patients were reported to have positive surgical margins. Regarding tumor stage, 19,377 patients presented with organ-confined disease and 18,669 with non-organ confined disease. The majority of the included studies were limited to urothelial bladder carcinoma, while 12 studies involved other tumor types, including squamous cell carcinoma, adenocarcinoma and small cell carcinoma. In addition, there were 5 studies [11, $14,15,20,29]$ in which the histopathological types were not described.
Study

ID

\section{Soave 2015}

Satkunasivam 2015

Reder 2015

Raza 2015

Kanatani 2015

Gakis 2015

Albisinni 2015

Nieuwenhuijzen 2014

Lin 2014

Kluth 2014

Bruins 2014

Bachir 2014

Lotan 2013

Sonpavde 2011

Tilki 2010

Canter 2009

Overall (I-squared $=32.1 \%, p=0.105)$
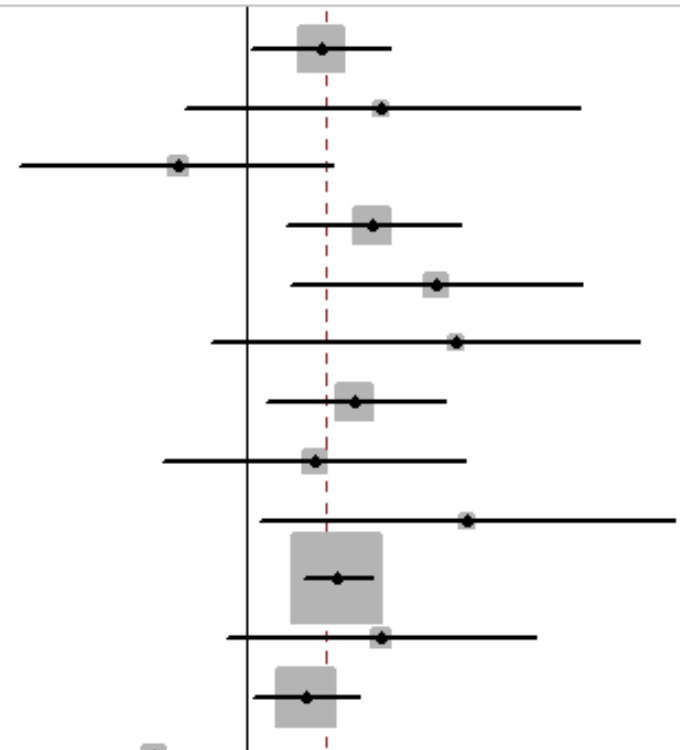

$1.58(1.03,2.41) \quad 7.40$

$2.29(0.68,7.69) \quad 0.91$

$0.66(0.25,1.70) \quad 1.46$

$2.16(1.27,3.68) \quad 4.74$

$3.20(1.31,7.82) \quad 1.69$

$3.60(0.80,11.00) 0.78$

$1.94(1.13,3.35) \quad 4.54$

$1.51(0.60,3.79) \quad 1.58$

$3.87(1.09,13.71) 0.84$

$1.74(1.41,2.15) \quad 30.11$

$2.27(0.88,5.83) \quad 1.50$

$1.43(1.03,1.98) \quad 12.66$

$0.57(0.25,1.31) \quad 1.95$

$2.50(1.42,4.41) \quad 4.18$

$1.38(1.07,1.78) \quad 20.32$

$1.58(0.96,2.61) \quad 5.36$

$1.63(1.46,1.83) \quad 100.00$

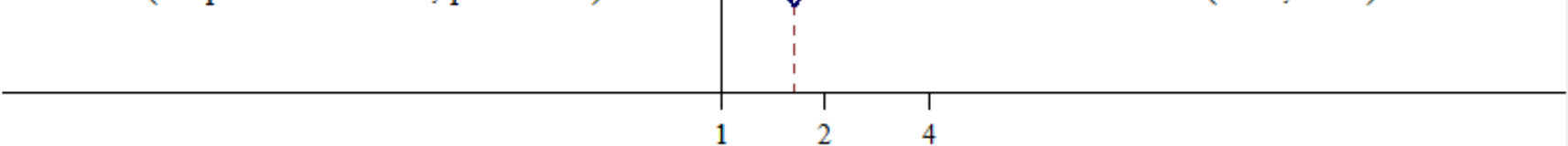

Figure 2: Meta-analysis of studies that examined the association between positive surgical margin and recurrence-free survival (RFS) following radical cystectomy (RC). 


\section{Meta-analysis}

In 16 studies, with a total sample size of 10,738 individuals, the associations between positive surgical margin and RFS of bladder cancer patients after RC were reported. A fixed effects model was used, revealing a summary relative risk estimate (SRRE) of 1.63 [95\% confidence interval (CI), 1.46-1.83; Figure 2], with no significant heterogeneity found (Q statistic, $P=0.105 ; \mathrm{I}^{2}$ $=32.1 \%$ ). The pooled result indicated that the presence of positive surgical margins was associated with poor RFS. The CSS was reported in 26 studies that enrolled a total of 25,804 bladder cancer patients. A random effects model was used due to evidence of heterogeneity among the studies ( $\mathrm{Q}$ statistic, $P=0.001 ; \mathrm{I}^{2}=54.5 \%$ ). A significant CSS disadvantage was detected in the positive surgical margin group compared with the negative surgical margin group (SRRE, 1.82; 95\% CI, 1.63-2.04; Figure 3). In addition, patients with positive surgical margins were found to have an increased risk in terms of OS (SRRE, 1.68 ; 95\% CI, 1.58-1.80; Figure 4), without evidence of heterogeneity (Q statistic, $P=0.805 ; \mathrm{I}^{2}=0.0 \%$ ).

In sensitivity analyses excluding one study at a time, the SRRE for RFS ranged from 1.59 (95\% CI, 1.38-1.83) to 1.71 (95\% CI, 1.50-1.94). Similarly, the SRRE for CSS ranged from 1.77 (95\% CI, 1.60-1.97) to $1.86(95 \%$ CI, 1.65-2.09), and the SRRE for OS ranged from 1.67

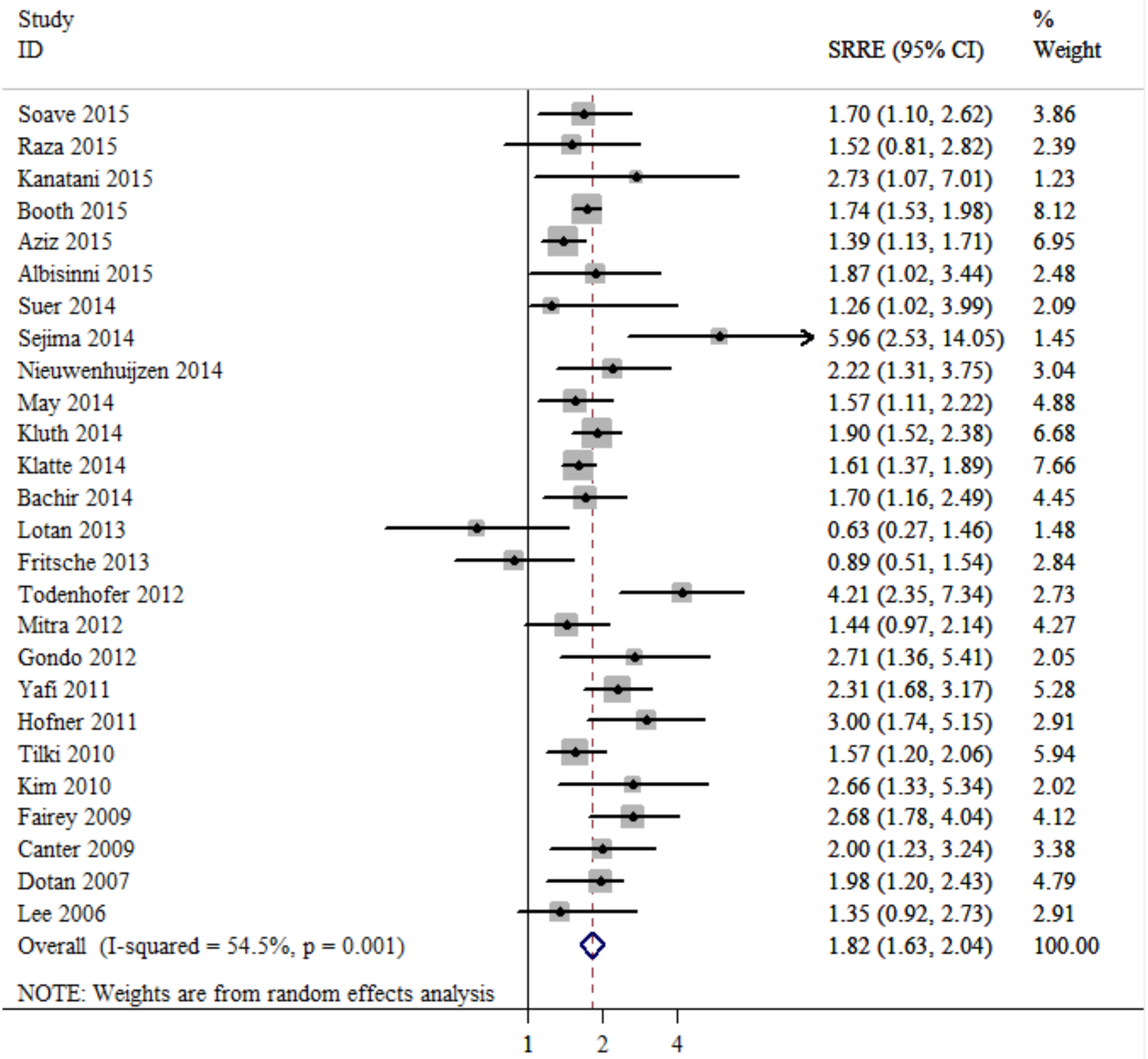

Figure 3: Meta-analysis of studies that examined the association between positive surgical margin and cancer-specific survival (CSS) following radical cystectomy (RC). 
(95\% CI, 1.55-1.80) to 1.71 (95\% CI, 1.59-1.84). These results indicated that the findings were reliable and robust. No statistical evidence of publication bias was found in this meta-analyses, as assessed by Begg's and Egger's tests for RFS ( $p$-Begg $=0.300$; p-Egger $=0.442$; Figure $5 \mathrm{~A}), \operatorname{CSS}(\mathrm{p}-\mathrm{Begg}=0.252 ; \mathrm{p}$-Egger $=0.194 ;$ Figure $5 \mathrm{~B})$ and $\operatorname{OS}(\mathrm{p}$-Begg $=0.649 ; \mathrm{p}$-Egger $=0.480 ;$ Figure $5 \mathrm{C})$, respectively.

\section{Test of heterogeneity}

Subgroup and meta-regression analyses were conducted to explore the source of heterogeneity according to mean patient age $(\geq 65 v s .<65)$, sample size $(\geq 500 v s .<500)$, publication year $(\geq 2014$ vs. $<2014)$, duration of follow-up ( $\geq 60$ months vs. $<60$ months), study type (single center vs. multicenter) and geographic region (North America, Europe or Asia). Although no significant modifiers accounting for the inter-study heterogeneity were detected, the observed heterogeneity in CSS decreased significantly in some models, such as articles published since 2014, multicenter studies, study with sample size $>500$ cases, and with follow-up duration $>60$ months. Furthermore, the results in subgroup analyses were consistent with the primary findings (Table 2).

\section{DISCUSSION}

RC with urinary diversion is the gold standard treatment for muscle-invasive bladder cancer or high-risk and recurrent superficial bladder cancer. According to a multi-institutional database of 888 bladder cancer patients who underwent RC, the 5-year RFS and CSS rates were 58

Study

ID

SRRE $(95 \%$ CI) Weight

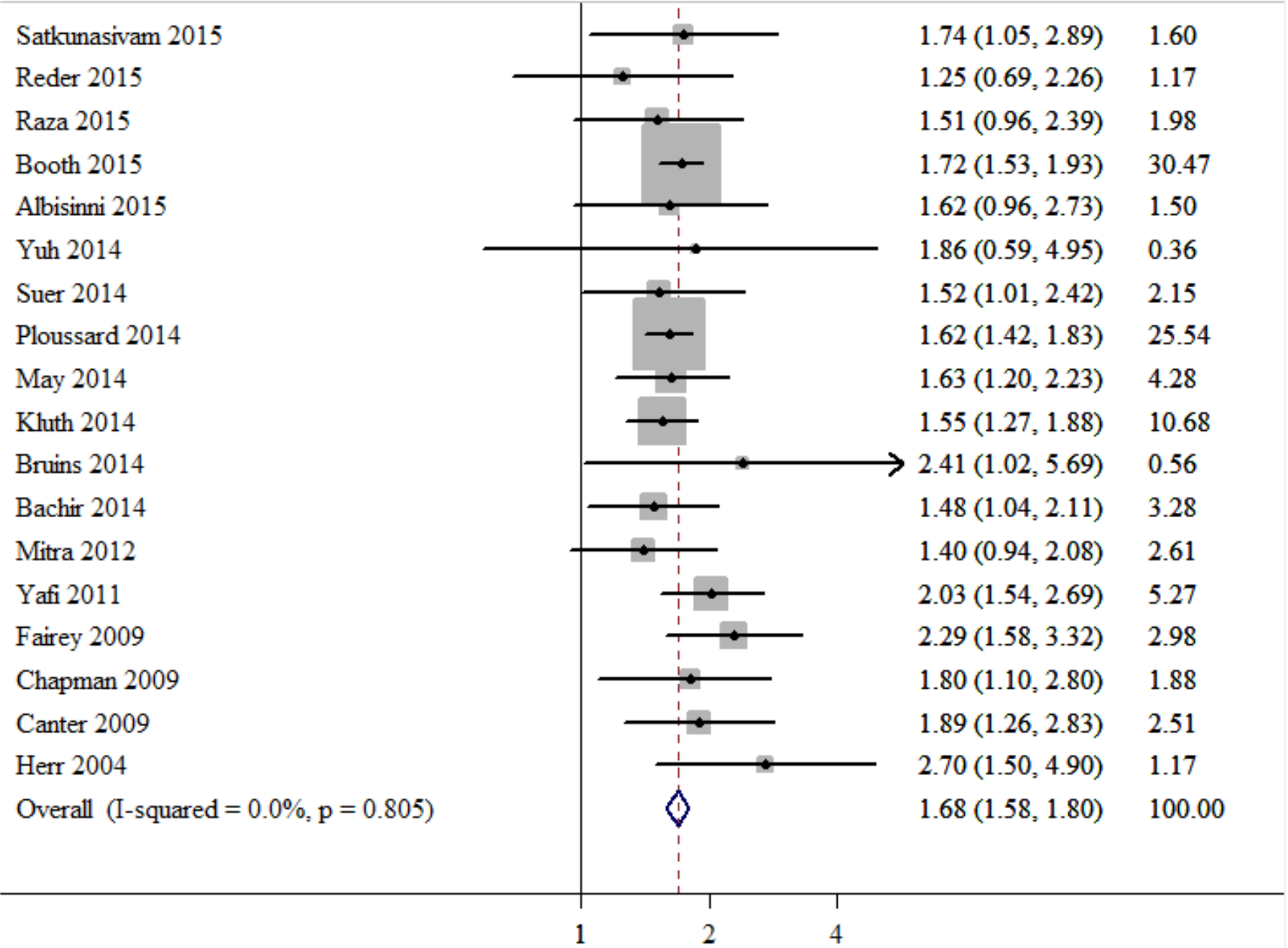

Figure 4: Meta-analysis of studies that examined the association between positive surgical margin and overall survival (OS) following radical cystectomy (RC). 
and $66 \%$, respectively [42]. However, regarding bladder cancer patients with advanced tumor stage, lymph node involvement, lymphovascular invasion and high tumor grade, $>50 \%$ experience systemic relapse and $\sim 50 \%$ develop distant metastases $[43,44]$. Therefore, identifying further potential predictive markers will be useful for the prognosis and management of bladder cancer patients treated with RC.

To the best of our knowledge, the present study is the first meta-analysis of the association between positive surgical margins and outcomes of bladder cancer treated with RC. Novara G et al [6] had evaluated the prognostic relevance of surgical margin status in a multicentre study of more than 4,400 patients treated with RC. they recommended that surgical margin status should be reported in pathological reports following $\mathrm{RC}$, and should prompt consideration of further adjuvant therapy for the patient. The past few years have seen growing much debate on surgical margin status and outcomes of bladder cancer after RC. However, until a prospective, randomized-controlled study is done, the findings from a meta-analysis of retrospective studies are the best evidence available.

In this analysis, 36 cohort studies were included, with a large sample size of 38,384 bladder cancer patients. This study provided relatively robust evidence demonstrating that the presence of positive surgical margins was associated with poor outcomes in terms of RFS, CSS and OS in bladder cancer patients treated with RC. The SRREs of positive surgical margins, and RFS, CSS and OS were 1.63 (95\% CI, 1.46-1.83), 1.82 (95\% CI, 1.63-2.04) and 1.68 (95\% CI, 1.58-1.80), respectively, compared with negative surgical margins. The findings were consistently independent of age, sample size, publication year, follow-up duration, study type and geographical region. The sensitivity analyses indicated that the findings were reliable and robust. In addition, there was no evidence of significant publication bias in these analyses according to Begg's or Egger's tests.

Heterogeneity is often a major concern in metaanalyses. Significant heterogeneity was detected in the analysis of the CSS model, although there was no evidence of heterogeneity in terms of RFS or OS. Many confounding variables differed across the individual studies, including age, gender, pathological stage and lymph node status; this may explain the observed heterogeneity between the studies. To address the issue of heterogeneity, subgroup analyses were conducted, revealing that the significant variations were reduced in the meta-analysis of article subgroups published since 2014 , with a multicenter design, with a sample size $>500$ patients and with follow-up duration $>60$ months.

Potential risk factors contributing to positive surgical margins are as follows: i) features of advanced cancer, such as lymphovascular invasion, extravesical disease and mixed histology [4]; ii) surgeon-dependent factors, including the type of procedure, technique and experience; and iii) specimen handling and accurate interpretation of $\mathrm{RC}[45,46]$. Due to the significant adverse associations between positive surgical margins and outcomes of bladder cancer after RC, interest in the preventive management of positive surgical margins has arisen. Although intraoperative frozen section analysis of the urethral margin prior to urinary tract reconstruction has been accepted as a standard practice [47], there is much debate concerning its usefulness in determining ureteral and urethral margin status [8, 48]. Further research is required to accurately evaluate the costs and benefits of intraoperative frozen section analysis for patients treated by RC.

Several important strengths of the present study should be noted. Firstly, the meta-analysis included 36 studies with a large sample size to detect more stable associations and provide more reliable results. Secondly,
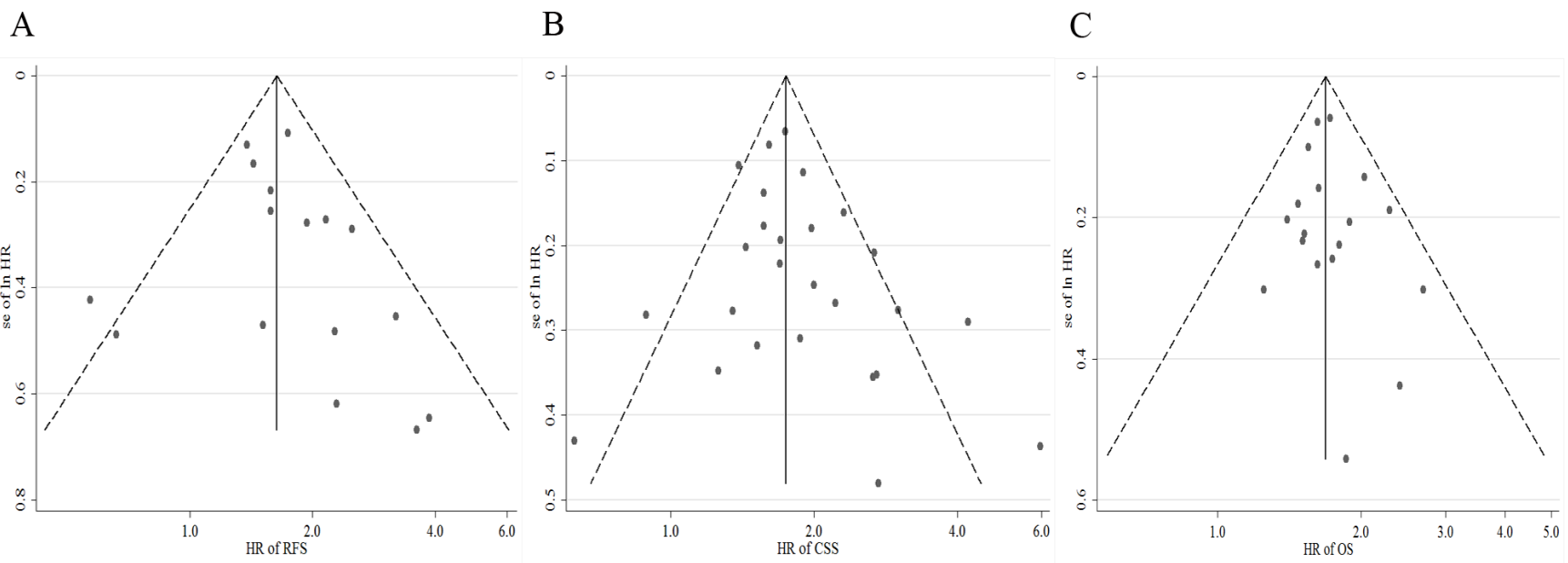

Figure 5: Funnel plots for publication bias of the hazard ratios (HRs) of (A) recurrence-free survival (RFS), (B) cancer-specific survival (CSS), and (C) overall survival (OS). 
strict accordance with the inclusion and exclusion criteria was maintained, and we also extracted available data from relevant studies that mentioned the relationship between surgical margin status and survival outcomes of bladder cancer patients after RC. Furthermore, the results were found to be reliable and robust through subgroup and sensitivity analyses.

However, the study was subject to several limitations. First and foremost, the majority of the included studies were retrospective cohort studies, which made our meta-analysis sensitive to potential confounding variables. Additionally, although the results from the main multivariable model that included the most adjusted confounders were used, there may be residual or unknown confounding variables that were not taken into consideration in the included studies. Secondly, substantial heterogeneity was observed in the meta-analysis of CSS. Although subgroup and meta-regression analyses were conducted to explore the source of heterogeneity, no effect modifier of heterogeneity was found. Thirdly, we were unable to explore the potential differences in associations according to the classification of bladder cancer. It remains unknown whether the findings may vary by tumor subtype or tumor stage, even though some subgroup analyses were conducted. An additional limitation is that the detection methods of surgical margin status were not definitely described in the majority of the included studies. Therefore, a subgroup analysis for detection methods could not be performed. Moreover, other detailed information regarding the features of the margins, such as the location, focality, and microscopic or macroscopic features, were also not presented in the included studies, and could not be further examined.

In summary, the present meta-analysis confirms that bladder cancer patients with positive surgical margins, as compared with negative surgical margins, are likely to have poorer RFS, CSS and OS after RC, indicating that surgical margin status may be an independent indicator of the survival outcome of patients with bladder cancer following RC.

\section{MATERIALS AND METHODS}

\section{Search strategy}

This meta-analysis was performed in accordance with the Preferred Reporting Items for Systematic Reviews and Meta-analyses (PRISMA) guidelines [49]. A systematic literature search was performed in the Pubmed, Embase and the Cochrane Library databases to identify eligible studies published between the inception of the databases and April 2016. The primary search string included the following items: 'bladder cancer', 'transitional cell carcinoma' or 'urinary bladder neoplasms'; 'margin' or 'margins'; 'surgery' or 'radical cystectomy'. The search was focused on human studies. No additional filters were included to restrict the search. Furthermore, a manual search of the reference lists of relevant review articles was conducted to identify all available studies.

\section{Inclusion and exclusion criteria}

The eligibility of each study was assessed using the population, intervention, comparator, outcome and study design (PICOS) approach [49]. A study was included in the analysis if it met the following criteria: the bladder cancer patient was treated with RC (P); the surgical margin was assessed by pathologists (I); the oncological outcomes with positive surgical margins were compared with negative surgical margins (C); the results were reported as risk estimates (hazard ratios, risk ratios, odds ratios) with corresponding 95\% confidence intervals, or sufficient data was provided to estimate these $(\mathrm{O})$; and the study was a prospective or retrospective cohort design (S).

In addition to these criteria, only studies that reported survival outcomes, such as RFS, CSS or OS, were considered for inclusion. Case-reports, reviews, expert opinions or meeting abstracts without usable data were excluded. In studies with the same or overlapping population, only the most recent and informative study was included in the meta-analysis.

\section{Data extraction}

Data from all included studies were independently extracted by two investigators and corroborated by another investigator. The following information was extracted for each included study: first author, year of publication, study type, country, study period, duration of follow-up, sample size, mean age, gender, pathological stage, positive lymph node rate, positive surgical margin rate, and risk estimates of RFS, CSS or OS based on margin status. If one study contained multiple data sets, the one with more adjusted confounders was used. All discrepancies in data extraction were resolved by discussion.

\section{Statistical analysis}

All included studies used multivariable Cox proportional hazards ratio models to examine the associations between surgical margin status and survival outcomes of RC, including RFS, CSS or OS. SRRES and $95 \%$ CIs were calculated in order to compare the positive margin group with the negative margin group. Heterogeneity between studies was assessed using the $\mathrm{Q}$ and $\mathrm{I}^{2}$ statistics. $P<0.10$ or $\mathrm{I}^{2}>50 \%$ were used to indicate heterogeneity. Random effects models were used for meta- 
analysis in cases of heterogeneity. Forest plots were also applied to assess the relationships between margin status and survival outcomes of bladder cancer treated by RC.

Subgroup and meta-regression analyses were performed to examine potential sources of heterogeneity according to age, sample size, publication year, follow-up duration, study type and geographical region. Sensitivity analyses were conducted to assess the robustness of the results by repeating the meta-analysis after omitting one study at a time. Furthermore, funnel plots were inspected for asymmetry, and Begg's and Egger's tests were used to assess publication bias. All statistical analyses were conducted using STATA 12.0 software (StataCorp LP, College Station, TX, USA). $P<0.05$ was considered to be an indicator of significance, except where specifically noted.

\section{ACKNOWLEDGMENTS AND FUNDING}

This work was supported by the Dean's Research Fund of Nanfang Hospital, Southern Medical University (no. $2013 \mathrm{C} 022$ to F.L.), the Natural Science Foundation of Guangdong Province of China (no. 2014A030310424 to F.L.; and no. 2015A030313289 to W.L.T.), Guangdong Provincial Science and Technology Projects (no. 2013B022000067 to W.L.T.) and the National Natural Science Foundation of China (no. 81272844 to W.L.T.), Scientific Research Foundation of the Health and Family Planning Commission of Hunan Province of China (no. B2016020 to T.Q.L).

\section{CONFLICTS OF INTEREST}

We declare that we have no conflicts of interest.

\section{REFERENCES}

1. Siegel RL, Miller KD, Jemal A. Cancer statistics, 2016. CA Cancer J Clin. 2016; 66: 7-30.

2. Gakis G, Efstathiou J, Lerner SP, Cookson MS, Keegan KA, Guru KA, Shipley WU, Heidenreich A, Schoenberg MP, Sagaloswky AI, Soloway MS, Stenzl A. ICUD-EAU International Consultation on Bladder Cancer 2012: Radical cystectomy and bladder preservation for muscle-invasive urothelial carcinoma of the bladder. Eur Urol. 2013; 63: 45-57.

3. Abdollah F, Gandaglia G, Thuret R, Schmitges J, Tian Z, Jeldres C, Passoni NM, Briganti A, Shariat SF, Perrotte P, Montorsi F, Karakiewicz PI, Sun M. Incidence, survival and mortality rates of stage-specific bladder cancer in United States: a trend analysis. Cancer Epidemiol. 2013; 37: 219225.

4. Dotan ZA, Kavanagh K, Yossepowitch O, Kaag M, Olgac S, Donat M, Herr HW. Positive Surgical Margins in Soft Tissue Following Radical Cystectomy for Bladder Cancer and Cancer Specific Survival. Journal of Urology. 2007; 178: 2308-2313.

5. Hadjizacharia P, Stein JP, Cai J, Miranda G. The impact of positive soft tissue surgical margins following radical cystectomy for high-grade, invasive bladder cancer. World Journal of Urology. 2009; 27: 33-38.

6. Novara G, Svatek RS, Karakiewicz PI, Skinner E, Ficarra V, Fradet Y, Lotan Y, Isbarn H, Capitanio U, Bastian PJ, Kassouf W, Fritsche HM, Izawa JI, et al. Soft Tissue Surgical Margin Status is a Powerful Predictor of Outcomes After Radical Cystectomy: A Multicenter Study of More Than 4,400 Patients. Journal of Urology. 2010; 183: 21652170 .

7. Lee SE, Byun SS, Hong SK, Chang IH, Kim YJ, Gill MC, Song SH, Kim KT. Significance of cancer involvement at the ureteral margin detected on routine frozen section analysis during radical cystectomy. Urol Int. 2006; 77: 1317.

8. Reder NP, Maxwell SP, Pambuccian SE, Barkan GA. Diagnostic accuracy of intraoperative frozen sections during radical cystectomy does not affect disease-free or overall survival: A study of 364 patients with urothelial carcinoma of the urinary bladder. Annals of Diagnostic Pathology. 2015; 19: 107-112.

9. Lotan Y, Bagrodia A, Passoni N, Rachakonda V, Kapur P, Arriaga Y, Bolenz C, Margulis V, Raj GV, Sagalowsky AI, Shariat SF. Prospective evaluation of a molecular marker panel for prediction of recurrence and cancer-specific survival after radical cystectomy. European Urology. 2013; 64: 465-471.

10. Satkunasivam R, Hu B, Metcalfe C, Ghodoussipour SB, Aron M, Cai J, Miranda G, Gill I, Daneshmand S. Utility and significance of ureteric frozen section analysis during radical cystectomy. BJU International. 2015; 117:463-468.

11. Booth CM, Siemens DR, Wei X, Peng Y, Berman DM, Mackillop WJ. Pathological factors associated with survival benefit from adjuvant chemotherapy (ACT): A populationbased study of bladder cancer. BJU International. 2015; 116: 373-381.

12. Yuh B, Torrey RR, Ruel NH, Wittig K, Tobis S, Linehan J, Lau CS, Chan KG, Yamzon J, Wilson TG. Intermediate-term oncologic outcomes of robot-assisted radical cystectomy for urothelial carcinoma. Journal of Endourology. 2014; 28: 939-945.

13. Lin J, Deibert CM, Holder D, Benson MC, McKiernan JM. The role of pelvic lymphadenectomy in non-muscle invasive bladder cancer. Canadian Journal of Urology. 2014; 21: 7108-7113.

14. Bachir BG, Aprikian AG, Izawa JI, Chin JL, Fradet Y, Fairey A, Estey E, Jacobsen N, Rendon R, Cagiannos I, Lacombe L, Lattouf JB, Kapoor A, et al. Effect of body mass index on the outcomes of patients with upper and lower urinary tract cancers treated by radical surgery: Results from a Canadian multicenter collaboration. Urologic Oncology: Seminars and Original Investigations. 
2014; 32: 441-448

15. Mitra AP, Quinn DI, Dorff TB, Skinner EC, Schuckman AK, Miranda G, Gill IS, Daneshmand S. Factors influencing post-recurrence survival in bladder cancer following radical cystectomy. BJU International. 2012; 109: 846-854.

16. Yafi FA, Aprikian AG, Chin JL, Fradet Y, Izawa J, Estey E, Fairey A, Rendon R, Cagiannos I, Lacombe L, Lattouf JB, Bell D, Drachenberg D, et al. Contemporary outcomes of 2287 patients with bladder cancer who were treated with radical cystectomy: a Canadian multicentre experience. BJU Int. 2011; 108: 539-545.

17. Fairey AS, Jacobsen NE, Chetner MP, Mador DR, Metcalfe JB, Moore RB, Rourke KF, Todd GT, Venner PM, Voaklander DC, Estey EP. Associations between comorbidity, and overall survival and bladder cancer specific survival after radical cystectomy: results from the Alberta Urology Institute Radical Cystectomy database. J Urol. 2009; 182: 85-92; discussion 3.

18. Chapman DM, Pohar KS, Gong MC, Bahnson RR. Preoperative hydronephrosis as an indicator of survival after radical cystectomy. Urologic Oncology: Seminars and Original Investigations. 2009; 27: 491-495.

19. Canter D, Guzzo TJ, Resnick MJ, Bergey MR, Sonnad SS, Tomaszewski J, VanArsdalen K, Malkowicz SB. A Thorough Pelvic Lymph Node Dissection in Presence of Positive Margins Associated With Better Clinical Outcomes in Radical Cystectomy Patients. Urology. 2009; 74: 161165.

20. Herr HW, Faulkner JR, Grossman HB, Natale RB, DeVere White R, Sarosdy MF, Crawford ED. Surgical factors influence bladder cancer outcomes: A cooperative group report. Journal of Clinical Oncology. 2004; 22: 2781-2789.

21. Soave A, John LM, Dahlem R, Minner S, Engel O, Schmidt S, Kluth LA, Fisch M, Rink M. The Impact of Tumor Diameter and Tumor Necrosis on Oncologic Outcomes in Patients with Urothelial Carcinoma of the Bladder Treated with Radical Cystectomy. Urology. 2015; 86: 92-98.

22. Albisinni S, Rassweiler J, Abbou CC, Cathelineau X, Chlosta P, Fossion L, Gaboardi F, Rimington P, Salomon L, Sanchez-Salas R, Stolzenburg JU, Teber D, Van Velthoven R. Long-term analysis of oncological outcomes after laparoscopic radical cystectomy in Europe: Results from a multicentre study by the European Association of Urology (EAU) section of Uro-technology. BJU International. 2015; 115: 937-945.

23. Nieuwenhuijzen JA, De Vries RR, Van Tinteren H, Bex A, Van Der Poel HG, Meinhardt W, Horenblas S. Followup after cystectomy: Regularly scheduled, risk adjusted, or symptom guided?: Patterns of recurrence, relapse presentation, and survival after cystectomy. European Journal of Surgical Oncology. 2014; 40: 1677-1685.

24. May M, Brookman-May S, Burger M, Gilfrich C, Fritsche HM, Rink M, Chun F, Fisch M, Roghmann F, Noldus J, Mayr R, Pycha A, Novotny V, et al. Concomitant Seminal Vesicle Invasion in pT4a Urothelial Carcinoma of the
Bladder with Contiguous Prostatic Infiltration is an Adverse Prognosticator for Cancer-Specific Survival after Radical Cystectomy. Annals of Surgical Oncology. 2014; 21: 40344040.

25. Bruins HM, Arends TJ, Pelkman M, Hulsbergen-van de Kaa CA, van der Heijden AG, Witjes JA. Radical cystectomy in a Dutch University hospital: long-term outcomes and prognostic factors in a homogeneous surgery-only series. Clin Genitourin Cancer. 2014; 12: 190-195.

26. Fritsche HM, May M, Denzinger S, Otto W, Siegert S, Giedl C, Giedl J, Eder F, Agaimy A, Novotny V, Wirth M, Stief C, Brookman-May S, et al. Prognostic value of perinodal lymphovascular invasion following radical cystectomy for lymph node-positive urothelial carcinoma. Eur Urol. 2013; 63: 739-744.

27. Todenhofer T, Renninger M, Schwentner C, Stenzl A, Gakis G. A new prognostic model for cancer-specific survival after radical cystectomy including pretreatment thrombocytosis and standard pathological risk factors. BJU Int. 2012; 110: E533-540.

28. Hofner T, Haferkamp A, Knapp L, Pahernik S, Hadaschik B, Djakovic N, Wagener N, Hohenfellner M. Preoperative hydronephrosis predicts advanced bladder cancer but is not an independent factor for cancer-specific survival after radical cystectomy. Urologia Internationalis. 2011; 86: 2530.

29. Kanatani A, Nakagawa T, Kawai T, Naito A, Sato Y, Yoshida K, Nozaki K, Nagata M, Yamada Y, Azuma T, Suzuki M, Fujimura T, Fukuhara H, et al. Adjuvant chemotherapy is possibly beneficial for locally advanced or node-positive bladder cancer. Clinical Genitourinary Cancer. 2015; 13: e107-e112.

30. Suer E, Ozcan C, Gokce I, Gulpinar O, Gogus C, Turkolmez $\mathrm{K}$, Baltaci S, Beduk Y. Do blood groups have effect on prognosis of patients undergoing radical cystectomy? Int Urol Nephrol. 2014; 46: 1521-1526.

31. Sejima T, Morizane S, Yao A, Isoyama T, Saito M, Amisaki T, Koumi T, Takenaka A. Prognostic impact of preoperative hematological disorders and a risk stratification model in bladder cancer patients treated with radical cystectomy. International Journal of Urology. 2014; 21: 52-57.

32. Gondo T, Nakashima J, Ozu C, Ohno Y, Horiguchi Y, Namiki K, Yoshioka K, Ohori M, Hatano T, Tachibana M. Risk stratification of survival by lymphovascular invasion, pathological stage, and surgical margin in patients with bladder cancer treated with radical cystectomy. International Journal of Clinical Oncology. 2012; 17: 456-461.

33. Kim DS, Cho KS, Lee YH, Cho NH, Oh YT, Hong SJ. High-grade hydronephrosis predicts poor outcomes after radical cystectomy in patients with bladder cancer. Journal of Korean medical science. 2010; 25: 369-373.

34. Raza SJ, Wilson T, Peabody JO, Wiklund P, Scherr DS, Al-Daghmin A, Dibaj S, Khan MS, Dasgupta P, Mottrie A, Menon M, Yuh B, Richstone L, et al. Long-term oncologic outcomes following robot-assisted radical cystectomy: 
Results from the international robotic cystectomy consortium. European Urology. 2015; 68: 721-728.

35. Gakis G, Ali-El-Dein B, Babjuk M, Hrbacek J, Macek P, Burkhard FC, Thalmann GN, Shaaban AA, Stenzl A. Urethral recurrence in women with orthotopic bladder substitutes: A multi-institutional study. Urologic Oncology: Seminars and Original Investigations. 2015; 33: 204e17$204 \mathrm{e} 23$.

36. Aziz A, Shariat SF, Roghmann F, Brookman-May S, Stief CG, Rink M, Chun FK, Fisch M, Novotny V, Froehner M, Wirth MP, Schnabel MJ, Fritsche HM, et al. Prediction of cancer-specific survival after radical cystectomy in pT4a urothelial carcinoma of the bladder: Development of a tool for clinical decision-making. BJU International. 2015; 117 : 272-279.

37. Ploussard G, Shariat SF, Dragomir A, Kluth LA, Xylinas E, Masson-Lecomte A, Rieken M, Rink M, Matsumoto K, Kikuchi E, Klatte T, Boorjian SA, Lotan Y, et al. Conditional survival after radical cystectomy for bladder cancer: Evidence for a patient changing risk profile over time. European Urology. 2014; 66: 361-370.

38. Kluth LA, Xylinas E, Rieken M, El Ghouayel M, Sun M, Karakiewicz PI, Lotan Y, Chun FK, Boorjian SA, Lee RK, Briganti A, Roupret M, Fisch M, et al. Impact of perioperative blood transfusion on the outcomes of patients undergoing radical cystectomy for urothelial carcinoma of the bladder. BJU Int. 2014; 113: 393-398.

39. Klatte T, Xylinas E, Rieken M, Roupret M, Fajkovic H, Seitz C, Karakiewicz PI, Lotan Y, Babjuk M, de Martino M, Shariat SF. Effect of ABO blood type on mortality in patients with urothelial carcinoma of the bladder treated with radical cystectomy. Urol Oncol. 2014; 32: 625-630.

40. Sonpavde G, Khan MM, Svatek RS, Lee R, Novara G, Tilki D, Lerner SP, Amiel GE, Skinner E, Karakiewicz PI, Bastian PJ, Kassouf W, Fritsche HM, et al. Prognostic risk stratification of pathological stage T3N0 bladder cancer after radical cystectomy. Journal of Urology. 2011; 185: 1216-1221.

41. Tilki D, Svatek RS, Karakiewicz PI, Isbarn H, Reich O, Kassouf W, Fradet Y, Novara G, Fritsche HM, Bastian PJ, Izawa JI, Stief CG, Ficarra V, et al. Characteristics and Outcomes of Patients With pT4 Urothelial Carcinoma at Radical Cystectomy: A Retrospective International Study of 583 Patients. Journal of Urology. 2010; 183: 87-93.
42. Shariat SF, Karakiewicz PI, Palapattu GS, Lotan Y, Rogers CG, Amiel GE, Vazina A, Gupta A, Bastian PJ, Sagalowsky AI. Outcomes of radical cystectomy for transitional cell carcinoma of the bladder: a contemporary series from the Bladder Cancer Research Consortium. The Journal of urology. 2006; 176: 2414-2422.

43. Montie JE, Clark PE, Eisenberger MA, El-Galley R, Greenberg RE, Herr HW, Hudes GR, Kuban DA, Kuzel TM, Lange PH, Lele SM, Michalski J, Patterson A, et al. Bladder cancer. J Natl Compr Canc Netw. 2009; 7: 8-39.

44. Malkowicz SB, van Poppel $\mathrm{H}$, Mickisch $\mathrm{G}$, Pansadoro V, Thuroff J, Soloway MS, Chang S, Benson M, Fukui I. Muscle-invasive urothelial carcinoma of the bladder. Urology. 2007; 69: 3-16.

45. Herr H, Lee C, Chang S, Lerner S. Standardization of radical cystectomy and pelvic lymph node dissection for bladder cancer: A collaborative group report. Journal of Urology. 2004; 171: 1823-1827.

46. Herr HW, Faulkner JR, Grossman HB, Crawford ED. Pathologic evaluation of radical cystectomy specimens: A cooperative group report. Cancer. 2004; 100: 2470-2475.

47. Witjes JA, Comperat E, Cowan NC, De Santis M, Gakis G, Lebret T, Ribal MJ, Van der Heijden AG, Sherif A. EAU guidelines on muscle-invasive and metastatic bladder cancer: summary of the 2013 guidelines. Eur Urol. 2014; 65: 778-792.

48. Kim HS, Moon KC, Jeong CW, Kwak C, Kim HH, Ku $\mathrm{JH}$. The clinical significance of intra-operative ureteral frozen section analysis at radical cystectomy for urothelial carcinoma of the bladder. World J Urol. 2015; 33: 359-365.

49. Liberati A, Altman DG, Tetzlaff J, Mulrow C, Gotzsche PC, Ioannidis JP, Clarke M, Devereaux PJ, Kleijnen J, Moher D. The PRISMA statement for reporting systematic reviews and meta-analyses of studies that evaluate health care interventions: explanation and elaboration. J Clin Epidemiol. 2009; 62: e1-34. 